\title{
A novel treatment for prevention of post-traumatic elbow stiffness using onaBotulinum toxin type A: a prospective placebo controlled randomized trial
}

\author{
Henrik C. Bäcker, Christina E. Freibott, Eric Swart, Carsten Perka, Charles M. Jobin, Melvin P. Rosenwasser
}

From the Department of Orthopedic Surgery, New York Presbyterian/Columbia University Medical Center, New York, New York.

\begin{abstract}
Approximately $30 \%$ of all upper extremity fractures are elbow fractures which may result elbow stiffness. This study aimed to investigate the efficacy of onaBotulinum Toxin type $A$ injection to prevent post-traumatic pain and elbow-stiffness. All patients were included who presented to a single surgeon with supracondylar/ intraarticular distal humerus fractures, proximal ulna and radius fractures. The study was developed in a randomized placebo controlled study between 2003-2007. The Disabilities of the Arm, Shoulder, and Hand (DASH) score as well as the arc-of-motion (AOM) were assessed after three, six, twelve-months and final follow up for evaluation. Of the 31-patients included, 15-patients $\mathbf{( 4 8 . 4 \% )}$ received Botox injections. In all patients no complication was observed when injecting a dosage 100-units for the brachialis and biceps brachii muscles. Furthermore, it was an effective method to prevent post-traumatic elbow stiffness, lasting sixmonths. Significant differences in DASH, VAS-score and ROM after three-months between the Botox and control group (DASH 21.6 \pm 11.0 vs. $\mathbf{5 5 . 3} \pm 11.0$; VAS $1.2 \pm 5.2$ vs. $5.7 \pm 21.9$; ROM $103 \pm 7.6$ vs. $73 \pm 6.3$; p>0.05) were identified in the prospective group. Botulinum toxin is a safe, reliable and effective treatment to prevent post-traumatic elbow stiffness.
\end{abstract}

Conflict of Interest: The authors declare that they have no conflict of interest.

Funding: This study was partwise funded by Allergan.

Ethical approval: This article does contain a study with human participants. IRB approval was obtained prior patient recruitment.

Informed consent: Informed consent was obtained from all individual participants included in the study.

Level of Evidence: Therapeutic II, Randomized Control Trial.
Our study demonstrates improved early range-ofmotion $(p<0.05)$, better extension after 6 weeks and improved functional outcome including VAS and DASH score $(\mathbf{p}<0.05)$.

Keywords : Elbow ; trauma ; stiffness ; Botulinum toxin ; Monteggia fracture; fracture.

\section{INTRODUCTION}

Approximately $30 \%$ of all fractures in the upper extremity can be attributed to elbow fractures. One of the major complications is stiffness of the elbow, which can occur even after elbow dislocation leading to significant patient disability. (1-3) Biomechanical studies have shown that the functional arc of motion for flexion/ extension is

Henrik C. Bäcker ${ }^{1,2}, \mathrm{MD}$,

Christina E. Freibott ${ }^{1}$, BA,

- Eric Swart ${ }^{1}, \mathrm{MD}$,

- Carsten Perka ${ }^{2}, \mathrm{MD}$,

- Charles M. Jobin ${ }^{1}, \mathrm{MD}$,

- Melvin P. Rosenwasser ${ }^{1}, \mathrm{MD}$

${ }^{1}$ Department of Orthopedic Surgery, New York Presbyterian/ Columbia University Medical Center, New York, New York.

${ }^{2}$ University hospital Charité Berlin, Berlin, Germany.

Correspondence : Dr. Henrik C. Bäcker, Columbia University Medical Center, 622 West $168^{\text {th }}$ Street, PH-1164, New York, NY 10032, USA.

Email : henrik.baecker@sports-med.org

- 2021, Acta Orthopædica Belgica. 
$130^{\circ}-30^{\circ}-0^{\circ}$ and for pronation/ supination $50^{\circ}-0^{\circ}-$ $50^{\circ}$ in order to accomplish activities of daily living (ADL) (4). Even though most patients have higher functional demands, those who suffered from severe elbow trauma may not recover fully (5-9).

Causes of post traumatic elbow stiffness can be classified as intrinsic or extrinsic, which includes any intra-articular incongruity that acts as a mechanical block to motion. Extra-articular causes of stiffness include soft tissue contractures and formation of heterotopic ossification (1).

Although well skilled, specialized orthopaedic surgeons can minimize the intrinsic stiffness by proper reduction and fixation, extrinsic stiffness is more challenging to manage. After trauma, improvement in motion relates to effective pain treatment. Therefore, this may cause involuntary guarding leading to contractions of both flexor and extensor groups (10). Over time, this lack of mobility results in capsular contraction and longterm stiffness (11).

Once elbow stiffness is present, it is challenging to treat. Treatment options vary from noninvasive procedures like stretching out overtime, manipulation under anesthesia (3), to surgical interventions like capsular release, which show limited success and can be fraught with complications $(12,13,14)$.

In orthopaedic surgery, onaBotulinum Toxin type A is used in variety of diseases such as lateral epicondylitis, tendon repairs in the hand, Torticollis, and contractures after total knee and hip arthroplasty $(15,16,17,18,19)$. onaBotulinum toxin type $A\left(\right.$ Botox $\left.{ }^{\circledR}\right)$ is an exotoxin produced by Clostridium botulinum which is reported as safe causing reversible localized muscle paralysis (17).

Our aim is to develop an effective technique to prevent elbow stiffness using onaBotulinum Toxin type A. We hypothesize that the use of onaBotulinum toxin type A injections (onaBoNT-A) to weaken the flexors of the elbow temporarily, breaks the cycle of pain, co-contraction, and muscular guarding that ultimately leads to immobility and joint contracture. Therefore, it should increase arc of motion, resulting in decreased long-term disability as measured by standardized patient based functional outcome measures.

\section{MATERIALS AND METHODS}

We developed a prospective, randomized controlled trial between 2003 and 2007 to show the safety of the use of onabotulinum toxin type A (onaBoNT-A) and the effectiveness.

For this study, approval was obtained from the hospital's institutional review board and informed consent was acquired from all subjects prior to surgery (ClinicalTrials.gov Identifier: NCT01129583).

The prospective controlled randomized trial is portrayed schematically in Figure 1 based on the CONSORT guidelines (20). All surgeries where onaBotulinum Toxin type A was applied were either supracondylar/ intraarticular distal humerus fractures (e.g. intercondylar fractures), proximal ulna and radius fractures (e.g. Monteggia fractures) and treated by a single surgeon (senior author).

\section{Technique of onaBoNT-A injection}

For the onaBotulinum toxin type A injection technique, the anterior arm was re-prepped and draped after fixation of the fracture, closure of the skin and removal of the sterile tourniquet, (see Appendix A for specific techniques). The muscle bellies were palpated while being stretched passively and the needle was inserted through the fascia into the muscle. $100 \mathrm{U}$ of onaBotulinum toxin type A (human serum albumin and sodium chloride in a sterile, vacuum-dried form without preservatives) was injected with a 23 -gauge needle into each the musculotendonous endplate of the 2 heads of the biceps and the brachialis muscle bellies. This was reconstituted with $2 \mathrm{cc}$ of $0.9 \%$ sterile normal saline without preservatives. To avoid injury to the musculocutaneous nerve and the medial neurovascular structures, biceps injections were made more than $13 \mathrm{~cm}$ distal to the coracoid process and brachialis injections more than $17 \mathrm{~cm}$ distal to the coracoid process in the midline (21).) Control patients received similar injections of $2 \mathrm{cc}$ of sterile normal saline into each muscle bellies. All injections were performed by the senior author. 


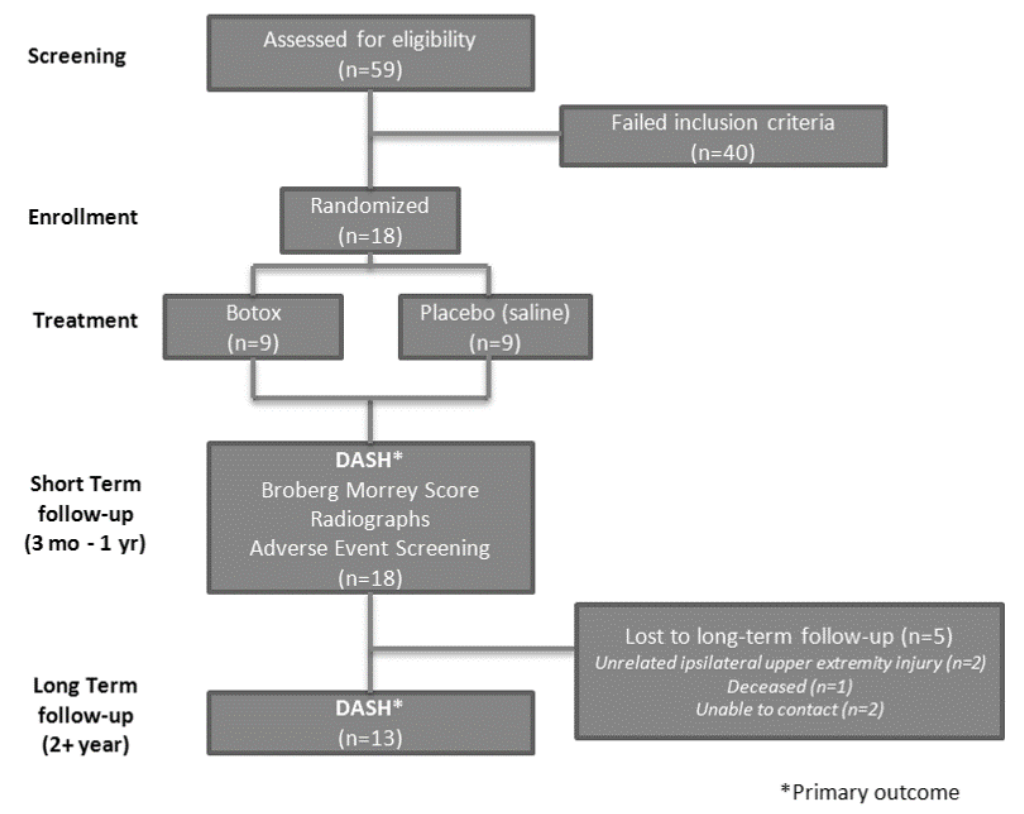

Figure 1. - Trial Flowsheet of the Randomized Control Trial

\section{Postoperative protocol}

All patients underwent the same postoperative protocol. A posterior splint was applied with the elbow in $30^{\circ}$ of flexion. Post-operatively, a standardized pain control protocol was applied for each patient. In patients where only bony reconstruction occurred, the arm was placed in a sling and swathe for comfort. In patients that had undergone ligamentous repair for elbow stability, a hinged orthotic brace was applied to protect the soft tissue as it healed.

Seven to ten days after surgery, the patients began physical therapy. Patients performed active range of motion (AROM) of the elbow several times daily. Rehabilitation visits were scheduled 2 to 3 times per week. For the next two weeks, AROM exercises progressed and light resistive exercises were initiated for the forearm, wrist and hand. Patients with a brace were allowed to remove the brace at home for short periods of time but remained in the brace during sleep and travel.

3.5 weeks postoperatively, the patients began strengthening exercises for elbow extension and flexion, beginning with very light weights (one-half to one pound), and in the gravity eliminated position. Gradually, while respecting patient tolerance, these resistive exercises progressed to heavier weights and/ or theraband in the against gravity position. Progression and improvement depended on a variety of factors including, pain tolerance, patient motivation, the severity of the original trauma and associated injuries, i.e. ulnar nerve involvement.

At six weeks following surgery, patients began strengthening exercises. Functional activities and resistive exercises progressed until the patients obtained their maximum rehabilitation potential. Physical therapy continued for at least six months following the procedure.

For the randomized control trial, the inclusion/ exclusion criteria were identical (see Table 1). The randomization process was performed by computergenerated allocation with use of sealed, opaque, numbered envelopes containing the treatment assignment. Following randomization, operative technique was the same for all patients based on their fracture type. A syringe containing $4 \mathrm{cc}$ of clear fluid was prepared by a research clinician outside of the operating room at the conclusion of the surgery. The prepared syringe was given to the senior surgeon for the injection. Patients randomized to the onaBoNT-A group received a total of $200 \mathrm{U}$ of onaBotulinum toxin type A reconstituted in a clear solution whereas those in the control group received 
Table 1. - Relevant inclusion and exclusion criteria

\begin{tabular}{|l|l|}
\hline \multicolumn{1}{|c|}{ Inclusion Criteria } & \multicolumn{1}{c|}{ Exclusion Criteria } \\
\hline - Capable of providing informed consent. & $\bullet$ Patients less than 18 years old \\
\hline$\bullet$ 18 years old and older & $\bullet$ Injuries that do not normally require surgical repair \\
\hline - Elbow fractures that require operative intervention including $:$ & $\bullet$ Patients with underlying spasticity \\
\hline$\circ$ Supracondylar distal humerus fractures & $\bullet$ Patients with burns about the elbow \\
\hline$\circ$ Intraarticular distal humerus fractures & $\bullet$ Patients with extensive soft tissue injuries of the elbow \\
\hline$\circ$ Proximal ulna and radius fractures & $\bullet$ Patients with head or spinal cord injuries \\
\hline & $\begin{array}{l}\bullet \text { Myasthenia gravis, Eaton-Lambert, ALS or any other } \\
\text { disease that interfere with neuromuscular function }\end{array}$ \\
\hline & $\begin{array}{l}\text { Use of aminoglycoside antibiotics or other drug therapies } \\
\text { that interfere with neuromuscular function }\end{array}$ \\
\hline
\end{tabular}

$4 \mathrm{cc}$ of clear $0.9 \%$ sterile saline. The patient and the surgeon were both blinded. The rehabilitation protocol is described below.

Likewise the prospective comparative trial, patients were followed at three months, six months and one year postoperatively. After two years, an elective follow-up visit was offered. The primary outcome was the DASH score and additionally VAS score. A secondary endpoint was set, which more accurately portrays a patient's clinical picture than simple ROM measurements (22-25). Therefore the Broberg-Morrey score, a secondary, physicianbased endpoint was chosen. This is a widely-used elbow function assessment tool which includes arc of motion data, but also includes information about elbow strength, stability, and pain (26).

The elbow arc of motion - flexion/extension - was measured. Furthermore, the radiographic evidence of union was qualitatively assessed by the senior surgeon. All physical exam measurements were obtained by a blinded, experienced research assistant.

\section{Statistics}

A post-hoc power analysis revealed that the study yielded an effect size of 2. Using conservative estimation, an effect size of 1.5 was assumed. In our subsequent prospective RCT, in order to achieve $80 \%$ power at the $5 \%$ significance level, 8 subjects would be needed in each arm (PASS 2008). Single-factor analysis of variance was used to compare continuous outcomes, including DASH score, Broberg-Morrey score, and arc of motion. An independent two-sided t-test was used to compare differences between groups, with significance set at $\mathrm{p}<0.05$.

\section{RESULTS}

\section{Randomized Control Trial}

Fifty-nine patients with operative elbow fractures were screened and included in the randomized Placebo controlled trial. In total, 18 (31\%) patients were enrolled over a period of 49 months between May 2003 and September 2007, of which 9 patients were treated with $100 \mathrm{U}$ of onaBoNT-A into each the biceps brachii and the brachialis muscles, and 9 patients were treated with saline injections. There were 7 females and 11 males, with an average age of 45 years (range 23-86) for the control group and 52 years (range 41-76) for the onaBoNT-A group. The dominant arm was involved in $55.6 \%$ in the control patients and $44.4 \%$ in the onaBoNT-A patients. Surgery was performed 7.6 days on average after injury (range 2 to 19 days) for the onaBoNT-A group and 8.6 days after injury (range 2 to 26 days) for the control group due to patient wish. No significant difference were observed for age $(\mathrm{p}=0.33)$, dominant side $(\mathrm{p}=0.66)$ and delay in surgery with $\mathrm{p}=0.78$. All patients underwent open reduction and internal fixation by a single surgeon (Table 2). 
Table 2. - Subject Demographics and Injury Descriptions, all fractures classified according to the AO classification.

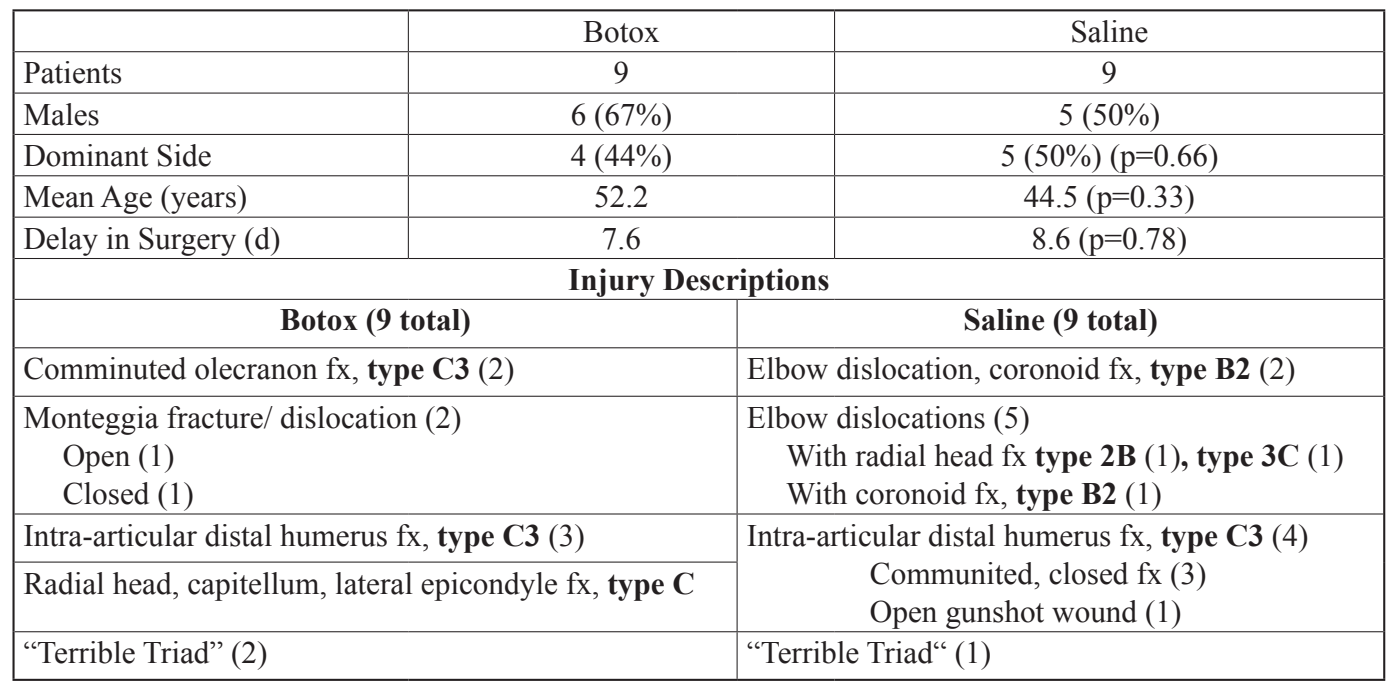

fx : fracture ; d : days.

15 patients $(83 \%)$ returned for the three-month visit, $16(89 \%)$ for the six month visit, $12(67 \%)$ for the one year visit and $13(72 \%)$ of the patients were seen at an average of 48 months post-operatively (range 24-81 months) for the long-term and final follow-up (average 4.0 years).

DASH scores showed significant disability in both groups (DASH score of 45 for all patients at three months follow-up), without any significant differences between the groups at three and six months. At one year and final follow-up (average 4.0 years), average DASH score was lower with positive trend in the onaBoNT-A group $(27 \pm 11.0$ after one year respectively $11 \pm 7.1)$ compared to the control group (54 \pm 7.6 respectively $37 \pm 8.7$ ) with high trend, but without statistical significance $(p=0.09$ after one year, respectively $p=0.06$ after two years) (Table 4). However, when looking for the VAS score, there was a significant difference observed at one year follow-up $(12.4 \pm 5.2$ vs. 56.6 $\pm 21.9 ; \mathrm{p}<0.05)$ (Table 4, Figure 2B). In terms of arc of motion there was a significant difference $(\mathrm{p} \leq 0.01)$ between the onaBoNT-A group $103^{\circ}$ \pm 7.6 compared to the control group $73^{\circ} \pm 6.3$ after three months (Table 3, Figure 2A). After six months the average arc of motion was also greater in the onaBoNT-A group $\left(105^{\circ} \pm 6.5 \mathrm{vs.} 88^{\circ} \pm 7.5\right)$, without statistical significance $(\mathrm{p}=0.10)$. At one

\section{VAS - (RCT)}

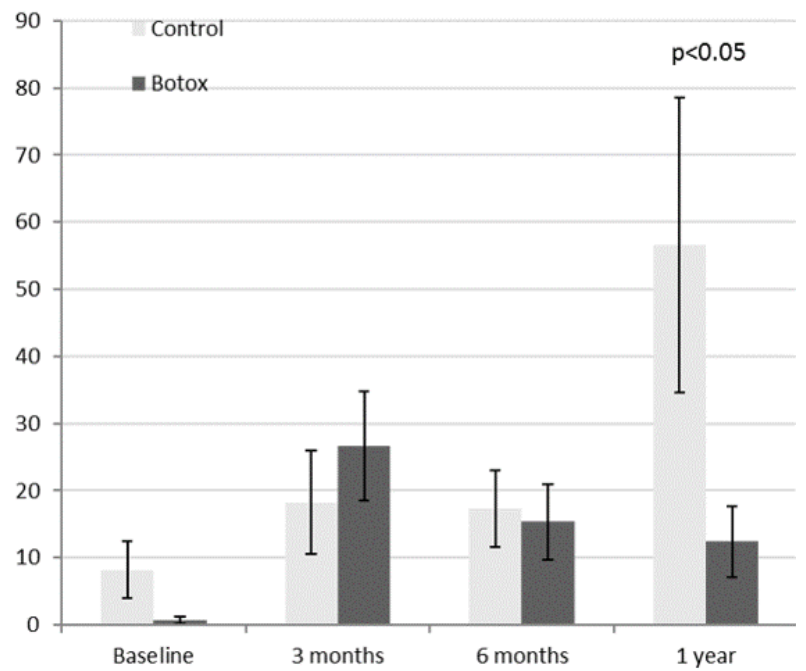

Figure 2. - VAS in the Randomized Control Trial.

year, arc of motion was virtually identical $\left(105^{\circ}\right.$ vs. $103^{\circ}$ ).

Additionally, elbow function assessment using the Broberg-Morrey score was higher for the onaBoNT-A group at all-time points in comparison to the control group with significant differences after six months $(82 \pm 1.9$ vs. $65 \pm 2.9, \mathrm{p}<0.05)$ (Table 3, Figure 3B). Similar positive tendency 
Table 3. - DASH and VAS Scores

\begin{tabular}{|l|c|c|c|}
\hline \multicolumn{1}{|c|}{$\begin{array}{c}\text { VAS score } \\
\text { Timepoint }\end{array}$} & Sotox & Saline & $p$ \\
\hline $\begin{array}{l}\text { Baseline } \\
\text { (at day of surgery) }\end{array}$ & $0.75 \pm 0.53$ & $0.22 \pm 4.29$ & 0.12 \\
\hline 3 months & $26.59 \pm 8.12$ & $18.23 \pm 7.71$ & 0.48 \\
\hline 6 months & $15.34 \pm 5.59$ & $17.32 \pm 5.72$ & 0.82 \\
\hline 1 year & $\mathbf{1 2 . 4 0} \pm \mathbf{5 . 2 3}$ & $\mathbf{5 6 . 6 0} \pm \mathbf{2 1 . 9 2}$ & $\underline{\mathbf{0 . 0 4}}$ \\
\hline $\begin{array}{c}\text { DASH Score } \\
\text { Timepoint }\end{array}$ & & & \\
\hline $\begin{array}{l}\text { Baseline } \\
\text { (at day of surgery) }\end{array}$ & $1.6 \pm 3.1$ & $1.2 \pm 1.5$ & 0.78 \\
\hline 3 months & $48 \pm 9.9$ & $41 \pm 9.2$ & 0.62 \\
\hline 6 months & $27 \pm 11$ & $56 \pm 9.8$ & 0.99 \\
\hline 1 year & $11 \pm 7.1$ & $37 \pm 8.7$ & $\underline{0.06}$ \\
\hline 2+ years* & & 36.0 \\
\hline
\end{tabular}

*Average time to follow-up $=4.0$ years was observed for the pain section of the BrobergMorrey score which showed lower average pain in onaBoNT-A group at all-time points, without statistical significances.

When looking at postoperative complications, we observed four patients with ulnar neuropathy, two in the control group and two in the onaBoNT-A group. All four underwent ulnar nerve decompression and anterior transposition in a subcutaneous fat flap at their initial open reduction internal fixation surgery. Two patients in the onaBoNT-A group had resolution of their ulnar nerve symptoms at their one-year follow-up while the two control patients had persistent pain and numbness in the fourth and fifth digits. One patient in the control group who had a terrible triad injury underwent a secondary

Table 4. - RCT Broberg + Morrey Scores, Arc of Motion

\begin{tabular}{|c|c|c|c|c|c|c|c|c|c|c|c|c|c|c|c|c|c|c|c|c|c|}
\hline \multirow{3}{*}{$\begin{array}{l}\text { Variable } \\
\mathrm{B}+\mathrm{M}\end{array}$} & \multicolumn{7}{|c|}{3 months } & \multicolumn{7}{|c|}{6 months } & \multicolumn{7}{|c|}{1 year } \\
\hline & \multicolumn{3}{|c|}{ Botox } & \multicolumn{3}{|c|}{ Saline } & \multirow{2}{*}{$\begin{array}{c}p \\
0.21\end{array}$} & \multicolumn{3}{|c|}{ Botox } & \multicolumn{3}{|c|}{ Saline } & \multirow{2}{*}{$\begin{array}{c}p \\
\underline{0.02} \\
\end{array}$} & \multicolumn{3}{|c|}{ Botox } & \multicolumn{3}{|c|}{ Saline } & \multirow{2}{*}{$\begin{array}{c}p \\
0.09 \\
\end{array}$} \\
\hline & 72 & \pm & 4.6 & 62 & \pm & 6.3 & & 82 & \pm & 1.9 & 65 & \pm & 2.9 & & 79 & \pm & 7.6 & 60 & \pm & 6.5 & \\
\hline $\mathrm{B}+\mathrm{M}$ pain score* & 7 & \pm & 2.2 & 11 & \pm & 2.7 & 0.22 & 7 & \pm & 1.9 & 14 & \pm & 2.9 & $\underline{0.07}$ & 8 & \pm & 2.7 & 22 & \pm & 6.4 & $\underline{0.06}$ \\
\hline Flexion & 119 & \pm & 5.5 & 107 & \pm & 3.2 & $\underline{0.09}$ & 123 & \pm & 3.1 & 111 & \pm & 5.2 & 0.11 & 128 & \pm & 6.5 & 128 & \pm & 7.0 & 0.98 \\
\hline Extension & 21 & \pm & 2.4 & 34 & \pm & 6.3 & $\underline{0.07}$ & 18 & \pm & 5.2 & 23 & \pm & 3.6 & 0.45 & 23 & \pm & 7.5 & 25 & \pm & 13 & 0.91 \\
\hline Arc of Motion & 103 & \pm & 7.6 & 73 & \pm & 6.3 & $\underline{0.01}$ & 105 & \pm & 6.5 & 88 & \pm & 7.5 & $\underline{0.10}$ & 105 & \pm & 13 & 103 & \pm & 14 & 0.94 \\
\hline Pronation & 67 & \pm & 9.9 & 80 & \pm & 8.5 & 0.34 & 84 & \pm & 2.9 & 74 & \pm & 8.5 & 0.23 & 81 & \pm & 3.7 & 75 & \pm & 6.3 & 0.43 \\
\hline Supination & 66 & \pm & 11 & 70 & \pm & 11 & 0.83 & 78 & \pm & 7.3 & 78 & \pm & 5.6 & 0.94 & 83 & \pm & 3.3 & 85 & \pm & 5.7 & 0.78 \\
\hline
\end{tabular}

* (based on the pain scale used in the Broberg Morrey grading system, rescaled where $0=$ no pain, $35=$ severe pain at rest)

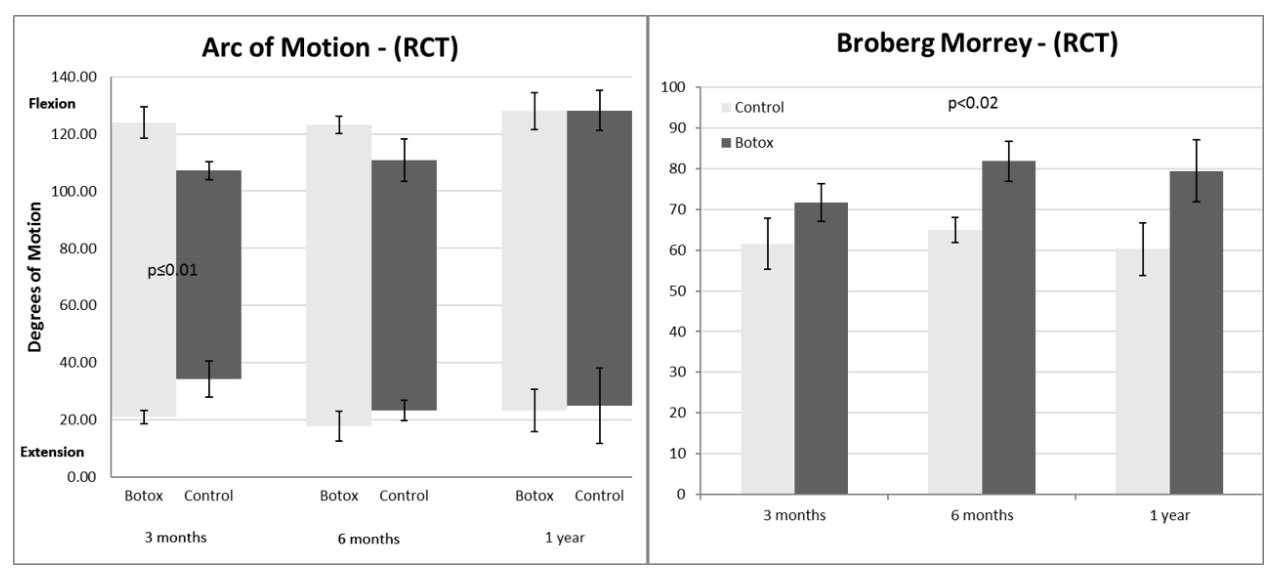

Figure 3. - A) Arc of Motion B) Broberg Morrey. 
surgery two weeks later for continued ulnohumeral instability, coronoid fracture fixation and lateral collateral ligament reconstruction. Three patients in the onaBoNT-A group also had secondary surgery. One patient with $\mathrm{C} 3$ distal humerus fracture had migration of K-wires and underwent a removal of hardware two years after his initial surgery which we donotroutinely perform in ourcenter. Another patient developed elbow stiffness, although he admitted to being noncompliant with his rehabilitation protocol. He underwent an open arthrotomy and $\mathrm{HO}$ excision, and at two year follow-up had an arc of motion from flexion/ extension $20^{\circ}$ to $120^{\circ}$. Another patient with a terrible triad injury and morbid obesity developed persistent elbow instability despite attempts at immediate postop immobilization and underwent application of a hinged elbow external fixator. One year later, he underwent removal of all hardware for MSSA infection. After six weeks of IV antibiotics, he was able to return to work and had an elbow arc of motion from 45 to $135^{\circ}$.

All patients had radiographic evidence of fracture union at one year. No patients had a nonunion of their fracture and three patients had evidence of mild heterotopic ossification on their latest radiograph. In addition, from the application of onaBoNT-A no complication was observed.

\section{DISCUSSION}

Traumatic elbow injuries constitute approximately $30 \%$ of fractures of the upper extremity, and represent some of the most complex and challenging injuries in orthopaedic surgery. Despite near anatomic reduction (intrinsic), outcomes are variable, and there is always significant concern for the development of post-operative stiffness resulting in severe disability. The currently available treatments for stiffness involve modifications in rehabilitation protocols and secondary capsular release surgery once contractures have already developed. In light of the mixed success and complication rate of revision surgery like capsular release, a simple, cost-effective, safe, minimally invasive procedure that can be performed at the time of initial fracture surgery to prevent posttraumatic stiffness has significant potential.
Prophylactic onaBotulinum Toxin type A injections into the brachialis and biceps brachii muscles show significant improvements in DASH and VAS score (one year after surgery), arc of motion (three months after surgery), BrobergMorrey score (six months after surgery) (Figures 2-3). Additionally many other positive tendencies were identified showing its potential to prevent elbow stiffness and improve patient outcome without any complications, and equal rates of bony healing.

The ensuing prospective randomized doubleblind, placebo-controlled, randomized trial was designed to eliminate bias caused by measurements and selection without randomization. In this trial, long-term scores showed improved function, although they did not quite reach statistical significance. Our long-term DASH scores were similar to those reported in other studies, which typically find DASH scores of 10 to 40 at a minimum of one year follow-up for complex intra-articular elbow fractures and dislocations $(6-8,27,28)$. The large variability in DASH scores in our study and in the literature illustrates the challenge inherent in quantifying outcomes in patients with such diverse injuries. Although there was no significant difference in our primary endpoint, onaBoNT-A significantly improved early postoperative arc of motion ( $\mathrm{p} \leq 0.05)$, as well as improved BrobergMorrey score $(\mathrm{p}<0.02)$.

According to the literature, a DASH score change of 19 or more indicated a "much better/ worse" outcome, whereas a mean score change of 10 expresses "somewhat better/ worse". This can be also interpreted as somewhat changed $(29,30)$. For the visual analog scale it depends even more on the pain score. For VAS scores less than 34, a significant difference was observed for changes of $13 \pm 14$. For higher VAS scores much greater changes were required for significant changes in pain; at 67 the significant changes were observed for more than $28 \pm 21$. Interestingly no significant changes could be identify between the two VAS scores (31). The Broberg-Morrey includes a variety of different parameters including strength, motion, stability and pain. Therefore, a categorical rating can be performed, where $95-100$ points describes an 
excellent outcome, 80-94 points a good one, 60-79 a fair and $<60$ a poor outcome (32).

For range of motion the changes are rather less relevant whereas the cut-offs between the functional ROM are most significant. This is defined as flexionextension $30^{\circ}-130^{\circ}$ with pronation-supination $50^{\circ}$ $50^{\circ}$ by Morrey (4). Furthermore, Sojbjerg described that the improvement in flexion is even more important than extension why patients are likely to recognize changes in flexion earlier (33).

Considering the changes in score and correlated patients' satisfaction, the Broberg-Morrey score improved from fair to good in the onaBoNT-A group among time. For saline it remained fair without any improvement in patient satisfaction. Likewise, the Flexion for both Saline and onaBoNT-A reached close to the functional range of motion with $23^{\circ}$ $128^{\circ}$ for onaBoNT-A respectively $25^{\circ}-128^{\circ}$ for Saline after 1 year. For DASH score higher changes in onaBoNT-A group were observed from 48 initially after fixation to 11 two years after surgery, whereas for saline the DASH score only changed by 4 points. Finally the VAS score improved significantly by 14 between 3 months and 1 year after surgery.

These quantitative measurements validated our anecdotal clinical observations that patients treated with onaBotulinum toxin type A appeared to benefit significantly more from early rehabilitation and regained elbow function more rapidly. We assume that rehabilitation and physical therapy is especially important directly after surgery. Once a satisfactory arc of motion, extension and flexion is achieved patients do not go to physical therapy anymore where as those patients who suffer from stiffness require more especially after 3 months. This may explain why at the beginning a significant difference was identified whereas at the endpoint no significant difference was present anymore.

Besides the neuronal and non-neuronal effect of onaBotulinum Toxin type $\mathrm{A}$, it does have a documented analgesic effect, but the exact nature of its role in pain modification and its impact has not been formally studied in large clinical trials (34). Even though it is used in the treatment of neuropathic pain with good results (35). We support these findings, and experienced less pain at six months and one year postoperatively with statistical significance. Furthermore, we believe that it may be related to better cartilage health and less cartilage contact pressure due to less scar tissue which cause stiffness and limitations in motion. In literature this was described to increase cartilage damage, leading to more release of proalgesic molecules $(36,37,38,39)$.

Since muscle contracture is defined as a velocity dependent increase of muscle resistance to passive stretch (40), it is most likely correlated to the viscoelastic environment due to the analytic approach. Patients are able to stretch better passively including stretching hyperreflexia or tendon muscle retraction (41,42). Also, the reduction in spasticity in flexion the oppositional spastic behaviors of the extensors are also decreased, which enables an early start stretching and therefore reduces stiffness. This relates to decreased resistance to muscle stretch and therefore increasing range of motion, although it is difficult to differentiate between the underlying neural - stretch reflex and the non-neuronal effect $(43,44)$. However, when looking for structural changes in literature no correlation with an increase in collagen and structure protein such as titin protein have been described (42).

Biomechanically, when injecting onaBotulinum Toxin type A into the muscle, the $\mathrm{HC}$ domain is binding to a polysialoganglioside receptor of the presynaptic membrane. Afterwards, it is binding to a protein receptor including synaptotagmin and glycosylated SV2. Then the onaBoNT-A can be internalized inside the synaptic vesicle which are directly recycled or fuse with the synaptic endosome and re-enter the synaptic vesicle. After acidification and accumulation of neurotransmitter, membrane translocation of the L chain into cytosolthe thioredoxin reductase-thioredoxin system and Hsp90 are activated the SNAP-25 and syntaxin are cleaved leading to a prolonged inhibition of neurotransmitter release and therefore paralysis (45).

Alternatively, onaBotulinum Toxin type A has a non-neuronal effect on cells in the skin which can facilitate wound healing, as well as decreasing the thickness of hypertrophic scares such as of the joint capsule (46). Since scar tissue is believed to come from a prolongation of the inflammatory phase and therefore, increased deposition of collagen and glycosaminoglycans due to repeated cycles of 
muscle micro-trauma (47,48), a disruption of dermal fibroblast cytoplasmic extension and increased local tissue water contents would decrease the scar hypertrophy (49). In addition, Neurotransmitters such as glutamate and substance $\mathrm{P}$ inhibits the release of inflammatory mediators including bradykinin, prostatglandins and serotonin (50). Another study described a selective effect on abnormal fibroblasts derived from hypertrophic scar (51). A combination of the neural and non-neuronal effect helps to treat contractures especially when applying direct after trauma and surgery. A reduction in hypertrophic scar, spasticity as well as pain facilitates early rehabilitation including physiotherapy. Therefore, even after total hip arthroplasty, knee arthroplasty and for the treatment of clubfoot it is applied (52).

In our cohort both effects - neuronal and nonneuronal - led to improvement in functional outcome. The neuronal effect caused a decrease spasticity and therefore, in resistance to muscle stretch, whereas the non-neuronal effect lowered the inflammatory response and scar tissue. Both effects, less scar tissue and less spasticity facilitate improved range of motion and subsequently functional outcome.

Although we do have some positive results and many positive tendencies, the lack of significance of our primary endpoint highlights the limited statistical power in all our RCT, which is a weakness of this study. Due to difficulties in recruiting patients and very specific inclusion criteria like the type of fracture (Supracondylar/ Intra-articular distal humerus fractures, Proximal ulna and radius fractures (e.g. Monteggia fractures)) and single surgeon treatment to avoid any bias on intrinsic stiffness, we were only able to enroll 18 patients. Those patients, who were excluded suffered from more than an isolated elbow injury, especially from head injuries or other neurological diseases, did not agree to participate, were operated from a different surgeon or presented with different fracture pattern. Additionally, only $67 \%$ of patients $(n=12 / 18)$ returned for the 1 -year, respectively $72 \%(n=13 / 18)$ for the 2-year follow-up. However, based on our post hoc power analysis, 8 subjects in each group were revealed, in order to achieve $80 \%$ power at the 5\% significance level (PASS 2008).
The ability to remain truly blinded was impossible, as the weakness in the elbow flexor muscles of patients receiving onaBoNT-A was clinically apparent upon examination in early follow-up intervals, and the resultant increased arc of motion was often striking. However, patient and surgeon were blinded during the surgery and at time of the application of onaBoNT-A or Saline. Since onaBoNT-A takes few weeks to see the effect, both were blinded up to the first follow up control. We feel that this problem highlights the early effectiveness of onaBoNT-A rather than detracts from the overall quality of the study. Although, according to the literature it is described that direct injection into the gastrocnemius muscle fails in up to $57 \%$, we could not observed any failure in our cohort (53).

The findings of our study are consistent with our hypothesis that temporary chemodenervation of the elbow flexors is a safe and effective way to prevent involuntary guarding and leads to increased benefit in the early rehabilitation period. Additionally, a significant difference in arc of motion was observed in short term as well as significant lower DASH and VAS scores in the long-term.

\section{CONCLUSION}

This study, shows promising and significant results. These results reflect the usefulness of onaBotulinum Toxin type A in preventing postoperative elbow stiffness, especially in complex elbow fractures and fracture-dislocations. It is a safe procedure that can improve early arc of motion and function significantly. Furthermore, there is a positive trend toward better long-term functional outcomes in the onaBotulinum Toxin type A group and significant reduction in pain postoperatively, even though the nature and the modification in pain is not yet fully understood.

\section{REFERENCES}

1. Bruno RJ, Lee ML, Strauch RJ, Rosenwasser MP. Posttraumatic elbow stiffness : evaluation and management. J Am Acad Orthop Surg. 2002 ; 10(2) : 106-16.

2. Lindenhovius AL, Jupiter JB. The posttraumatic stiff elbow : a review of the literature. J Hand Surg Am. 2007 ; 32(10) : 1605-23. 
3. Nandi S, Maschke S, Evans PJ, Lawton JN. The stiff elbow. Hand (N Y). 2009 ; 4(4) : 368-79.

4. Morrey BF, Askew LJ, Chao EY. A biomechanical study of normal functional elbow motion. J Bone Joint Surg Am. $1981 ; 63(6)$ : 872-7.

5. Atalar AC, Demirhan M, Salduz A, Kilicoglu O, Seyahi A. [Functional results of the parallel-plate technique for complex distal humerus fractures]. Acta Orthop Traumatol Turc. 2009 ; 43(1) : 21-7.

6. Athwal GS, Hoxie SC, Rispoli DM, Steinmann SP. Precontoured parallel plate fixation of AO/OTA type C distal humerus fractures. J Orthop Trauma. 2009 ; 23(8) : 575-80.

7. Kraus E, Harstall R, Borisch N, Weber D. [Primary total elbow replacement for complex intra-articular distal humerus fractures]. Unfallchirurg. $2009 ; 112(8)$ : 692-8.

8. Ek ET, Goldwasser M, Bonomo AL. Functional outcome of complex intercondylar fractures of the distal humerus treated through a triceps-sparing approach. J Shoulder Elbow Surg. 2008 ; 17(3) : 441-6.

9. Jupiter JB, Neff U, Holzach P, Allgower M. Intercondylar fractures of the humerus. An operative approach. $J$ Bone Joint Surg Am. 1985 ; 67(2) : 226-39.

10. Page C, Backus SI, Lenhoff MW. Electromyographic activity in stiff and normal elbows during elbow flexion and extension. J Hand Ther. 2003 ; 16(1) : 5-11.

11. Hildebrand KA, Zhang M, Hart DA. High rate of joint capsule matrix turnover in chronic human elbow contractures. Clin Orthop Relat Res. 2005 ; 439 : 228-34.

12. Lindenhovius AL, van de Luijtgaarden $K$, Ring $D$, Jupiter J. Open elbow contracture release : postoperative management with and without continuous passive motion. J Hand Surg Am. 2009 ; 34(5) : 858-65.

13. Ring D, Chin K, Jupiter JB. Radial nerve palsy associated with high-energy humeral shaft fractures. J Hand Surg Am. $2004 ; 29(1): 144-7$.

14. Kim SJ, Shin SJ. Arthroscopic treatment for limitation of motion of the elbow. Clin Orthop Relat Res. 2000(375) : 140-8.

15. Placzek R, Drescher W, Deuretzbacher G, Hempfing A, Meiss AL. Treatment of chronic radial epicondylitis with botulinum toxin A. A double-blind, placebo-controlled, randomized multicenter study. J Bone Joint Surg Am. 2007 ; 89(2) : 255-60.

16. Hayton MJ, Santini AJ, Hughes PJ, Frostick SP, Trail IA, Stanley JK. Botulinum toxin injection in the treatment of tennis elbow. A double-blind, randomized, controlled, pilot study. J Bone Joint Surg Am. 2005 ; 87(3) : 503-7.

17. Seyler TM, Smith BP, Marker DR, Ma J, Shen J, Smith TL, et al. Botulinum neurotoxin as a therapeutic modality in orthopaedic surgery : more than twenty years of experience. J Bone Joint Surg Am. 2008 ; 90 Suppl 4 : 133-45.

18. Bertoni M, Castagna A, Baricich A, Berti G, Lazzaretti S, Morandi C. Administration of type A botulinum toxin after total hip replacement. European journal of physical and rehabilitation medicine. 2008 ; 44(4) : 461-5.

19. Seyler TM, Marker DR, Bhave A, Plate JF, Marulanda GA, Bonutti PM, et al. Functional problems and arthrofibrosis following total knee arthroplasty. The Journal of bone and joint surgery. 2007 ; 89 Suppl 3 : 59-69.

20. Moher D, Schulz KF, Altman DG. The CONSORT statement: revised recommendations for improving the quality of reports of parallel-group randomised trials. Lancet. 2001 ; 357(9263) : 1191-4.

21. Yang ZX, Pho RW, Kour AK, Pereira BP. The musculocutaneous nerve and its branches to the biceps and brachialis muscles. The Journal of hand surgery. 1995 ; 20(4) : 671-5.

22. Ring D, Jupiter JB, Sanders RW, Mast J, Simpson NS. Transolecranon fracture-dislocation of the elbow. Journal of orthopaedic trauma. 1997 ; 11(8) : 545-50.

23. Lindenhovius AL, Jupiter JB, Ring D. Comparison of acute versus subacute treatment of terrible triad injuries of the elbow. The Journal of hand surgery. 2008 ; 33(6) : 920-6.

24. Egol KA, Immerman I, Paksima N, Tejwani N, Koval KJ. Fracture-dislocation of the elbow functional outcome following treatment with a standardized protocol. Bull NYU Hosp Jt Dis. 2007 ; 65(4) : 263-70.

25. Konrad GG, Kundel K, Kreuz PC, Oberst M, Sudkamp NP. Monteggia fractures in adults: long-term results and prognostic factors. J Bone Joint Surg Br. 2007 ; 89(3) : 35460.

26. Broberg MA, Morrey BF. Results of delayed excision of the radial head after fracture. The Journal of bone and joint surgery. $1986 ; 68(5)$ : 669-74.

27. Theivendran K, Duggan PJ, Deshmukh SC. Surgical treatment of complex distal humeral fractures : Functional outcome after internal fixation using precontoured anatomic plates. Journal of shoulder and elbow surgery / American Shoulder and Elbow Surgeons et al. 2009.

28. Gofton WT, Macdermid JC, Patterson SD, Faber KJ, King GJ. Functional outcome of AO type C distal humeral fractures. The Journal of hand surgery. 2003 ; 28(2) : 294308 .

29. Husted JA, Cook RJ, Farewell VT, Gladman DD. Methods for assessing responsiveness : a critical review and recommendations. $J$ Clin Epidemiol. 2000 ; 53(5) : 459-68.

30. Atroshi I, Gummesson C, Andersson B, Dahlgren E, Johansson A. The disabilities of the arm, shoulder and hand (DASH) outcome questionnaire : reliability and validity of the Swedish version evaluated in 176 patients. Acta Orthop Scand. $2000 ; 71(6): 613-8$.

31. Bird SB, Dickson EW. Clinically significant changes in pain along the visual analog scale. Ann Emerg Med. 2001 ; 38(6) : 639-43.

32. Longo UG, Franceschi F, Loppini M, Maffulli N, Denaro V. Rating systems for evaluation of the elbow. Br Med Bull. $2008 ; 87: 131-61$. 
33. Sojbjerg JO. The stiff elbow. Acta Orthop Scand. 1996 ; 67(6) : 626-31.

34. Ranoux D, Attal N, Morain F, Bouhassira D. Botulinum toxin type A induces direct analgesic effects in chronic neuropathic pain. Ann Neurol. 2008 ; 64(3) : 274-83.

35. Park J, Park HJ. Botulinum Toxin for the Treatment of Neuropathic Pain. Toxins (Basel). 2017 ; 9(9).

36. Driscoll C, Chanalaris A, Knights C, Ismail H, Sacitharan PK, Gentry C, et al. Nociceptive Sensitizers Are Regulated in Damaged Joint Tissues, Including Articular Cartilage, When Osteoarthritic Mice Display Pain Behavior. Arthritis Rheumatol. 2016 ; 68(4) : 857-67.

37. Kroon FPB, van Beest S, Ermurat S, Kortekaas MC, Bloem JL, Reijnierse M, et al. In thumb base osteoarthritis structural damage is more strongly associated with pain than synovitis. Osteoarthritis Cartilage. 2018; 26(9): 1196-202.

38. Sanchez-Adams J, Leddy HA, McNulty AL, O'Conor CJ, Guilak F. The mechanobiology of articular cartilage : bearing the burden of osteoarthritis. Curr Rheumatol Rep. $2014 ; 16(10): 451$.

39. Nakamura S, Arai Y, Takahashi KA, Terauchi R, Ohashi S, Mazda O, et al. Hydrostatic pressure induces apoptosis of chondrocytes cultured in alginate beads. J Orthop Res. 2006 ; 24(4) : 733-9.

40. Malhotra S, Pandyan AD, Day CR, Jones PW, Hermens H. Spasticity, an impairment that is poorly defined and poorly measured. Clin Rehabil. 2009 ; 23(7) : 651-8.

41. Tardieu C, Colbeau-Justin P, Bret MD, Lespargot A, Huet de la Tour E, Tardieu G. An apparatus and a method for measuring the relationship of triceps surae torques to tibio-tarsal angles in man. Eur J Appl Physiol Occup Physiol. 1976 ; 35(1) : 11-20.

42. Mathevon L, Michel F, Decavel P, Fernandez B, Parratte B, Calmels P. Muscle structure and stiffness assessment after botulinum toxin type A injection. A systematic review. Ann Phys Rehabil Med. 2015 ; 58(6) : 343-50.

43. Ozcakir S, Sivrioglu K. Botulinum toxin in poststroke spasticity. Clin Med Res. 2007 ; 5(2) : 132-8.
44. Wang R, Gaverth J, Herman PA. Changes in the Neural and Non-neural Related Properties of the Spastic Wrist Flexors After Treatment With Botulinum Toxin A in Poststroke Subjects: An Optimization Study. Front Bioeng Biotechnol. $2018 ; 6: 73$.

45. Pirazzini M, Rossetto O, Eleopra R, Montecucco C. Botulinum Neurotoxins: Biology, Pharmacology, and Toxicology. Pharmacol Rev. 2017 ; 69(2) : 200-35.

46. Grando SA, Zachary CB. The non-neuronal and nonmuscular effects of botulinum toxin : an opportunity for a deadly molecule to treat disease in the skin and beyond. Br J Dermatol. 2018 ; 178(5) : 1011-9.

47. Gassner HG, Brissett AE, Otley CC, Boahene DK, Boggust AJ, Weaver AL, et al. Botulinum toxin to improve facial wound healing: A prospective, blinded, placebocontrolled study. Mayo Clin Proc. 2006 ; 81(8) : 1023-8.

48. Al-Qattan MM, Al-Shanawani BN, Alshomer F. Botulinum toxin type A : implications in wound healing, facial cutaneous scarring, and cleft lip repair. Ann Saudi Med. 2013 ; 33(5) : 482-8.

49. Martel H, Walker DC, Reed RK, Bert JL. Dermal fibroblast morphology is affected by stretching and not by C48/80. Connect Tissue Res. 2001 ; 42(4) : 235-44.

50. Aoki KR. Pharmacology and immunology of botulinum toxin type A. Clin Dermatol. 2003 ; 21(6) : 476-80.

51. Haubner F, Ohmann E, Muller-Vogt U, Kummer P, Strutz J, Gassner HG. Effects of botulinum toxin a on cytokine synthesis in a cell culture model of cutaneous scarring. Arch Facial Plast Surg. 2012 ; 14(2) : 122-6.

52. Bhave A, Zywiel MG, Ulrich SD, McGrath MS, Seyler TM, Marker DR, et al. Botulinum toxin type A injections for the management of muscle tightness following total hip arthroplasty : a case series. J Orthop Surg Res. 2009 ; 4 : 34.

53. Schnitzler A, Roche N, Denormandie P, Lautridou C, Parratte B, Genet F. Manual needle placement : accuracy of botulinum toxin A injections. Muscle Nerve. 2012; 46(4) : 531-4.

\section{APPENDIX A}

\section{Operative Techniques}

Distal Humerus : We utilized the standard posterior midline triceps-splitting approach to the distal humerus. The ulnar nerve and branches of the radial nerve to the triceps were identified and protected throughout the procedure. For intra-articular fractures, the posterior elbow capsule was incised to expose the articular surfaces. In cases where visualization of the joint was not adequate or depending upon surgeon preference, an olecranon osteotomy was performed. The fracture fragments were identified and provisional fixation was obtained with K-wires. Cancellous screws were placed lateral to medial to reduce the medial and lateral columns and obtain articular congruence. The lateral column of the humerus was reduced to the shaft and fixed with a contoured reconstruction plate and the medial column plate was placed $90^{\circ}$ orthogonally. The coronoid and 
olecranon fossae were then inspected visually and digitally to ensure there was no encroachment. Ulnar nerve transposition was performed in patients who had baseline ulnar nerve symptoms.

Elbow Fracture Dislocations and Monteggia Equivalents : A posterior skin incision was made and extended proximally and distally to expose the distal humerus and the proximal ulnar shaft. After identification of the ulnar nerve and better visualization of the proximal ulna fracture through the ECU and FCU interval, reduction is obtained and fixed with contoured plates as indicated. In fractures with less comminution, a figure of eight tension band technique with 18 gauge wire was used. Through the same skin incision, the radial head is approached through a posterolateral approach. The fractured radial head was exposed and resected taking care to protect the annular ligament. Coronoid fractures that required repair were accomplished with suture or screw fixation and buttressing plates. If fixation of the coronoid fractures is not possible laterally, a medial approach is used. If the radial head fracture is found to be significantly comminuted, appropriately sized radial head prosthesis is inserted. The lateral collateral ligament complex is repaired and arc of motion and stability of the elbow is confirmed. 